\title{
Spatial and temporal variation in barnacle growth in a coastal upwelling system
}

\author{
Eric Sanford*, Bruce A. Menge \\ Department of Zoology, Oregon State University, Corvallis, Oregon 97331, USA
}

\begin{abstract}
Recent studies suggest that large-scale variation in nearshore primary productivity may strongly influence the dynamics of rocky intertidal communities. Among the hypothesized effects is a link between phytoplankton abundance and the growth of barnacles and other suspension feeders. We tested the strength of this association on the central coast of Oregon, USA, by quantifying watercolumn chlorophyll a $(\mathrm{chl}$ a) concentration and the growth of 2 intertidal barnacles (Balanus glandula and Chthamalus dalli). Barnacles were photographed at $13 \mathrm{~d}$ intervals on mid-intertidal growth plates attached in wave-exposed and wave-protected habitats at 2 sites differing in nearshore productivity: Strawberry Hill (SH) and Boiler Bay (BB), Oregon. B. glandula grew more rapidly in waveexposed areas than wave-protected habitats, presumably because higher flows delivered more food to passively feeding barnacles. After several months, individuals of both species attained a larger size at $\mathrm{SH}$, the site with consistently higher chl a concentrations. Surprisingly, short-term growth rates only partially matched spatial and temporal variations in phytoplankton. Growth rates were low during a persistent upwelling event, and increased 2- to 3-fold during the subsequent upwelling relaxation. At $\mathrm{SH}$, this increase coincided with a major phytoplankton bloom, but growth rates remained high well after chl a concentrations decreased. Moreover, parallel increases in growth were observed at $\mathrm{BB}$, despite the fact that no bloom was recorded at this site. These results imply that factors other than phytoplankton contributed to variation in barnacle growth. Records of barnacle settlement suggest that water-column concentrations of larvae increased dramatically at both sites during the period of high barnacle growth. Published analyses of stomach contents indicate that zooplankton may be an important food source in other barnacle species. Yet another factor, water temperature, was also elevated during the period of sustained barnacle growth. Increased barnacle growth during the upwelling relaxation may thus have arisen from the combined benefits of more phytoplankton, more zooplankton, and warmer water temperatures. Incorporating the influence of zooplankton and water temperature into studies of bottom-up influences may improve our ability to explain variation among intertidal communities.
\end{abstract}

KEY WORDS: Barnacles · Balanus glandula $\cdot$ Chthamalus dalli $\cdot$ Bottom-up factors · Phytoplankton · Zooplankton · Upwelling $\cdot$ Community ecology

\section{INTRODUCTION}

Recent studies suggest that nearshore productivity may have important 'bottom-up' influences on rocky intertidal communities (Menge 1992, Bustamante et al.

${ }^{*}$ Present address: Hopkins Marine Station, Stanford University, Pacific Grove, California 93950, USA.

E-mail: sanforde@leland.stanford.edu
1995). Studies along the coast of Oregon, USA, have identified persistent variation in productivity among sites separated by 10 s to 100 s of kilometers (Menge et al. 1997a,b, Menge unpubl. data). Sites with consistently higher concentrations of phytoplankton appear to have greater rates of recruitment and growth of sessile suspension feeders. Rates of grazing and predation also appear to be higher at these sites (Menge 1992, Menge et al. 1996, 1997a). These and similar studies in

๑) Inter-Research 2001 
South Africa (Bustamante et al. 1995) suggest that high levels of nearshore productivity may increase prey and algal production and thus support greater consumer abundances. These consumers may, in turn, exert stronger 'top-down' forces on lower trophic levels. Suspension-feeding invertebrates such as barnacles and mussels may thus be important links in the energy flow between primary producers and larger consumers including whelks, sea stars, and shorebirds (Baird et al. 1985, Menge 1992, Ricciardi \& Bourget 1999).

The influence of water-column conditions on barnacle growth has long been of interest to marine ecologists (Hatton \& Fischer-Piette 1932, Moore 1935). Although acorn barnacles are capable of generating feeding currents by actively sweeping their cirri through still water, feeding is generally passive at all but the lowest flow speeds (Trager et al. 1990, Sanford et al. 1994). In most habitats, barnacles simply orient their cirral net into the flow and passively collect suspended particles. Therefore, the flux of food to barnacles can be viewed as a function of both flow speed and particle concentration.

Not surprisingly, many early studies documented faster growth of acorn barnacles in areas that were exposed to either high flow (Hatton \& Fischer-Piette 1932, Moore 1935, Crisp 1960) or a high concentration of suspended matter (Moore 1936). Crisp (1960) suggested that factors influencing barnacle growth rates could be separated into local factors (including water flow and barnacle density) and regional factors (including temperature and 'richness of suspended nutrients'). Later studies supported the idea that among-site variation in concentrations of phytoplankton and detritus may influence rates of barnacle growth. In the Aleutian Islands, Duggins et al. (1989) found that intertidal barnacles Balanus glandula grew up to 5 times faster in kelp-dominated environments. The results of $\delta^{13} \mathrm{C}$ analysis confirmed that much of the input received by barnacles in these systems was derived from kelps, presumably in the form of suspended detritus. Bertness et al. (1991) found that growth of the barnacle Semibalanus balanoides was greater in Narragansett Bay, Rhode Island, than at outer coast sites where mean chlorophyll $a(\mathrm{chl} a$ ) concentrations were $\sim 6 \times$ lower.

Connections among suspended food, barnacle growth, and population dynamics have thus been suggested by a number of studies. More recently such connections have been viewed within a broader community or ecosystem context (Duggins et al. 1989, Menge 1992, Menge et al. 1997a,b). Attempts to understand variation among rocky intertidal communities have traditionally focused on local processes such as predation, herbivory, competition, and disturbance (see Paine 1994 for a general review), whereas the potential contribution of variation in pelagic productivity was largely overlooked. Models of community dynamics now incorporate large-scale, bottom-up influences as important sources of variation among intertidal communities (Roughgarden et al. 1988, Menge 1992, Menge et al. 1996, Connolly \& Roughgarden 1999).

As interest in large-scale processes has grown, researchers have advocated comparative approaches to examine the influence of oceanographic factors such as currents, nutrients, temperature, and phytoplankton abundance (Roughgarden et al. 1988, Menge 1992, Bustamante et al. 1995, Connolly \& Roughgarden 1998, Leonard et al. 1998, Menge et al. 1999, Sanford 1999). Caution must be used in drawing inferences from comparative studies because they necessarily rely on correlation. One approach to strengthen confidence in such studies is to combine spatial and temporal investigations of the factor of interest (Menge 1991). Previous studies have implicated the role of phytoplankton in barnacle growth by contrasting sites that varied in phytoplankton abundance (Moore 1936, Bertness et al. 1991, Menge 1992). In this study, we attempt to strengthen these inferences by adding a short-term temporal component to the quantification of barnacle growth.

Phytoplankton blooms along the central Oregon coast are brief (days to weeks) and appear to be linked to episodic upwelling. Blooms typically occur in nearshore waters within a few days of the cessation of strong northerly winds and thus appear to coincide with periods of upwelling relaxation (Menge et al. 1997b). We hypothesized that if growth is directly linked to phytoplankton abundance, then blooms should be reflected as brief spikes of rapid barnacle growth. We tested this hypothesis by quantifying short-term variation in phytoplankton abundance and barnacle growth rates. We focused on 2 species of acorn barnacles (Balanus glandula and Chthamalus dalli) at 2 rocky intertidal sites on the central Oregon coast known to have large, persistent differences in phytoplankton abundance. Our results document strong spatial and temporal variations in barnacle growth but suggest that phytoplankton abundance alone is insufficient to explain these patterns.

\section{MATERIALS AND METHODS}

Study sites. In 1994-1995, barnacle (Balanus glandula and Chthamalus dalli) growth was quantified in the mid-intertidal zone at Strawberry Hill (SH) $\left(44^{\circ} 15^{\prime} \mathrm{N}, 124^{\circ} 07^{\prime} \mathrm{W}\right)$ and Boiler Bay (BB) $\left(44^{\circ} 50^{\prime} \mathrm{N}\right.$, $\left.124^{\circ} 03^{\prime} \mathrm{W}\right), 2$ sites separated by $83 \mathrm{~km}$ on the central coast of Oregon, USA (Menge 1992, Menge et al. 1994, 1997b). The mid-intertidal zone at these sites is characterized by dense beds of the California mussel 
Mytilus californianus. Disturbance gaps within these beds contain a mixture of macroalgae and sessile suspension feeders including acorn barnacles B. glandula, C. dalli, and Semibalanus cariosus, gooseneck barnacles Pollicipes polymerus, and mussels (the bay mussel M. trossulus and juvenile $M$. californianus). Previous research indicated that the waters adjacent to our study sites differed strongly in phytoplankton concentrations during the upwelling season (typically May through September). Whereas chl a was consistently low at BB (generally $<5 \mu \mathrm{g} \mathrm{l}^{-1}$ ), $\mathrm{SH}$ was washed by episodic phytoplankton blooms during which chl a reached extremely high levels $\left(>30 \mu \mathrm{g} \mathrm{l}^{-1}\right.$ ) (Menge et al. $1997 \mathrm{a}, \mathrm{b})$.

In addition to examining the effects of variation in phytoplankton abundance, we quantified barnacle growth in wave-exposed and wave-protected habitats at each site. At $\mathrm{SH}$, the wave-exposed area was a series of irregular outcrops and benches broken up by large pools and surge channels. This area was directly exposed to breaking waves. In contrast, the wave-protected area was sheltered by numerous outcrops. The $\mathrm{BB}$ site consisted of 3 benches (each $\sim 75 \mathrm{~m}$ long) that ran perpendicular from the shore out into the ocean. Barnacle growth was examined at the extremes of this wave-exposure gradient (i.e. on the most exposed outer bench and on the most protected landward bench). Previous work at SH and BB quantified variation in flow (using rates of erosion of cylinders made of dental chalk) and maximum wave forces (using dynamometers) at these same locations (Menge et al. 1996).

Growth plate design. We quantified the growth rates of barnacles on $10 \mathrm{~cm} \times 13 \mathrm{~cm}$ clear acrylic plates (thickness: $6 \mathrm{~mm}$ ). Although barnacle cyprids are rarely able to persist on smooth acrylic, they will readily settle into shallow pits (Crisp 1960). Small pits (1.5 mm diameter, $0.5 \mathrm{~mm}$ deep) were thus drilled into each plate in a $6 \times 7$ rectangular array with $14 \mathrm{~mm}$ separating adjacent pits. In this way, barnacles were maintained under solitary conditions, thereby avoiding the influence of crowding on growth and morphology (Moore 1935, Barnes \& Powell 1950, Crisp 1960, Bertness et al. 1998). The density of barnacles growing on pitted plates does not affect growth rate until individuals come into direct physical contact with one another (Crisp 1960). In our study, the bases of adjacent barnacles were not touching even after more than 1 yr of growth.

Plates were attached to horizontal surfaces within pre-existing gaps in mid-intertidal mussel beds (Mytilus californianus). Efforts were made to ensure that barnacles growing on plates experienced environmental conditions similar to individuals growing on adjacent rock surfaces. Because a hydrodynamic boundary layer may form at the rock surface, barnacles growing on plates raised above the surrounding rock may experi- ence greater flows and wave forces than those on the rock (Denny 1988). To make the surface of plates flush with the rock, we used a rock hammer and chisel to create flat depressions, approximately $14 \mathrm{~cm}$ wide $\times$ $17 \mathrm{~cm}$ long $\times 0.6 \mathrm{~cm}$ deep (Fig. 1). To ensure that plates fitted snugly into these hollows, we placed a $2 \mathrm{~cm}$ strip of marine epoxy putty (Z-spar ${ }^{\mathrm{TM}}$ Splash Zone Compound, Seattle Marine, Seattle, Washington, USA) around the irregular edges of each depression. While the putty was hardening, we positioned a sample plate in the depression, pressing the edges of the plate into the putty. The plate was then removed, leaving a depression with straight edges into which a plate fitted exactly. In addition to minimizing flow artifacts, recessing plates into the rock probably kept them from overheating during periods of aerial exposure. Plates were held in place by a single stainless steel screw passing through a countersunk hole near the center of the plate and into a plastic wall anchor in the rock (Fig. 1). The underside of each plate was engraved with a unique number for identification.

Growth and mortality of naturally settling barnacles. Fifteen plates were spaced along approximately 35 to $40 \mathrm{~m}$ of shore within each of the 4 study areas ( $\mathrm{SH}$ exposed, $\mathrm{SH}$ protected, BB exposed, BB protected). All plates were haphazardly placed in mussel bed gaps at approximately $+1.5 \mathrm{~m}$ above mean lower low water. Plate sites were chiseled and prepared in March/April 1994 and all plates were deployed on 25 and 26 April.

In some geographic regions (e.g. New England and Scotland), barnacle settlement is limited to a discrete season lasting < 2 mo (Connell 1961, Wethey 1984, Bertness et al. 1998). By contrast, along the Pacific coast of North America, although many Balanus glandula and Chthamalus dalli cyprids arrive onshore during episodes of heavy settlement, small numbers of barnacle

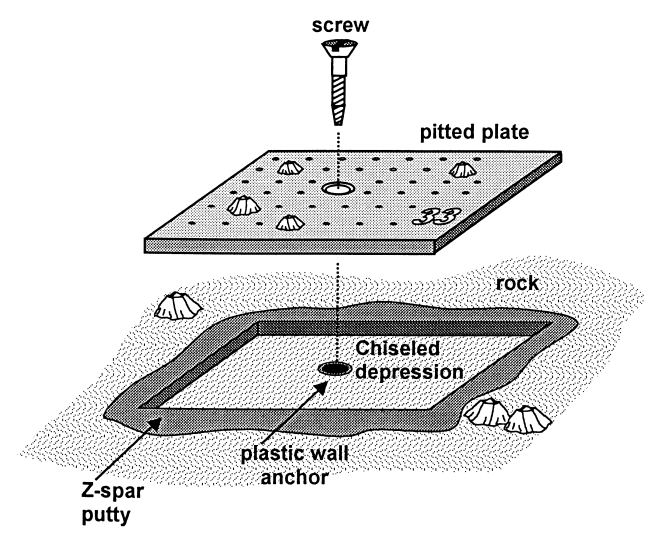

Fig. 1. Design of barnacle growth plates. Acrylic plates $(10 \times$ $13 \mathrm{~cm}$ ) were drilled with a regular array of pits and secured into shallow depressions chiseled into the rock. Plates were easily removed for censusing and photographic monitoring 
larvae settle intermittently during much of the year (Gaines et al. 1985, Strathmann 1987, Pineda 1994, Menge unpubl. data). In addition, post-settlement mortality of barnacles is often high (Wethey 1984, Gosselin \& Qian 1996; see also 'Results'). Therefore, in our system, it was difficult to know the age of barnacles on plates without regular observations through time.

Plates were thus briefly removed from the rock and censused in the field every 12 to $14 \mathrm{~d}$ until early September. Each pit was assigned coordinates to denote its position on the plate, and we recorded the presence or absence of cyprids and recent settlers in each pit. We assumed that settlement occurred in the middle of the period between consecutive census dates. In this way, the age of all barnacles growing on plates was estimated to within \pm 6 to $7 \mathrm{~d}$.

In addition to verifying the age of barnacles, the regular monitoring of plates allowed us to estimate variation in post-settlement mortality between sites, wave exposures, and settlement dates. We selected 2 monitoring dates (21 and 22 June, and 18 and 20 August) that had a large number of cyprids and newly metamorphosed settlers on all plates. The settlement date of these individuals was easily estimated ( \pm 6 to $7 \mathrm{~d}$ ) because their pits had been empty during the previous census. We examined post-settlement mortality of these cohorts by quantifying the percent of newly occupied pits on each plate that were empty after approximately $25 \mathrm{~d}$. Cases where an individual died and was replaced before the next sampling date were easily detected because of the shell morphology and small size of recently metamorphosed barnacles. Balanus glandula and Chthamalus dalli were grouped together for this analysis because it was not always possible to distinguish cyprids of the 2 species in the field. Estimates of mortality were conservative because we did not record cases where pits contained $>1$ cyprid (i.e. an occupied pit that was empty after $25 \mathrm{~d}$ sometimes represented the mortality of 2 individuals, rather than 1).

Growth of transplanted barnacles. During the first month of this study, settlement of Chthamalus dalli was very low on wave-exposed plates. We therefore transplanted C. dalli recruits to the study areas from an area of higher settlement. To do so, we constructed a separate set of $10 \mathrm{~cm} \times 13 \mathrm{~cm}$ acrylic plates. Pits were the same size and depth as above, but since $C$. dalli grows to a smaller adult size, the pits were more closely spaced ( $8 \mathrm{~mm}$ apart in an $11 \times 13$ grid). On 28 May, 14 plates were attached to the low intertidal zone on the wave-protected bench at BB (a location known to receive heavy settlement of $C$. dalli). By late June, recent $C$. dalli settlers and smaller numbers of Balanus glandula were present on most plates.

On 9 July, we randomly divided the plates into 2 groups and transplanted them to pre-chiseled loca- tions within the exposed areas at $\mathrm{SH}$ and $\mathrm{BB}(\mathrm{n}=7$ plates per site). All plates were removed and transplanted during a single low-tide period of aerial exposure. Prior to being transplanted, plates were photographed and censused to record the presence or absence of barnacles in each pit. It was thus possible to quantify the growth of barnacles that settled at the source site, rather than individuals that may have subsequently filled empty pits at the site of transplant. Transplanted barnacles were all of a similar size and represented a cohort of individuals that settled at the same location during the same time period. This design minimized potential differences that could arise from settlers arriving naturally at $\mathrm{SH}$ and $\mathrm{BB}$ on different days after experiencing different planktonic conditions (Jarrett \& Pechenik 1997).

Photographic monitoring. Plates were generally photographed every $13 \mathrm{~d}$ between 28 June and 8 September 1994. In total, short-term barnacle growth was assessed during 5 consecutive periods for the natural settlement plates, and 4 consecutive periods for transplanted plates. On sampling days, all plates at a site were briefly removed from the rock, placed on a blue background, and photographed with a $35 \mathrm{~mm}$ camera equipped with a macro-lens and mounted on a frame stand. A ruler was included in each photograph for scale. Although limpets on the plates generally kept barnacles free of algal growth, it was occasionally necessary to remove diatoms using a soft toothbrush.

Following the intensive monitoring of short-term growth rates, longer-term growth rates were monitored by photographing plates on a less frequent schedule. Plates were photographed on 17 and 19 October 1994, 1 and 3 December 1994, 14 and 16 April 1995, 12 and 13 June 1995, and 25 and 26 August 1995.

Image analysis. Short-term barnacle growth: Slides of barnacle plates were digitized and stored on a computer as JPEG images. We used image-analysis software (SigmaScan Pro v.4.0, Jandel Scientific Software, San Rafael, California, USA) to measure the maximum basal diameter $(\mathrm{mm})$ and the basal area $\left(\mathrm{mm}^{2}\right)$ of individual barnacles on plates. Measurements were calibrated using the ruler present in each photograph. Each barnacle was assigned a unique number based on its plate and location within the array of pits.

From images taken of the natural settlement plates, we measured both maximum basal diameter (the longest linear dimension) and basal area of individual Balanus glandula on each of the 6 sampling dates. There was no evidence that individuals that died before the last date were growing more slowly than those that persisted. We therefore considered only individuals that were present in the first photographs (28 and 29 June 1994) and persisted through all 5 growth periods (until 7 and 8 September 1994). 
Similarly, for the transplanted plates, we quantified the growth of all individuals (both Balanus glandula and Chthamalus dalli) that were present during all 4 periods. For barnacles on transplanted plates, only basal area was measured. Data confirmed that maximum basal diameter and basal area were tightly correlated (see 'Results') and thus that either measure was a sufficient indicator of size. In some photographs, small barnacles were obscured by diatoms. These individuals were removed from the analysis because their size could not be accurately measured and because the heavy cover of diatoms may have impeded their growth.

Image analysis. Longer-term growth and growth curves: To assess variation in longer-term Balanus glandula growth, we examined a separate group of barnacles that recruited to the natural settlement plates at $\mathrm{SH}$ exposed and $\mathrm{BB}$ exposed areas during August 1994. Since these individuals were known to have settled within the same 3 wk period, we simply measured their final basal area in mid-April 1995, after approximately 8 mo of growth. Photographs from September, October, and December 1994 were inspected to ensure that the same individuals were present throughout the entire growth period. For Chthamalus dalli, we assessed longer-term growth on transplanted plates by measuring the basal area of all individuals that persisted from June 1994 until mid-June 1995.

Whereas the above measures of growth focused on the final size attained, we also characterized the growth curve of wave-exposed Balanus glandula and Chthamalus dalli by examining changes in basal diameter across all sampling dates. For B. glandula, we identified all individuals that persisted on natural settlement plates from May/June 1994 until late August 1995. For these individuals ( $\mathrm{n}=17$ at $\mathrm{SH}_{i} \mathrm{n}=66$ at $\mathrm{BB}$ ), we measured maximum basal diameter from the 11 images taken of each plate between June 1994 and August 1995.

For Chthamalus dalli, we characterized the growth curve of individuals transplanted to the exposed area at SH. From the large number of $C$. dalli that survived from June 1994 to June 1995, we randomly selected 10 individuals per plate. We followed these barnacles through time by measuring their basal diameter from the images taken on all 9 sampling dates.

Water temperature and chlorophyll concentrations. Water temperatures were recorded every hour by data-loggers (Model 9102, Alpha Omega, Corvallis, Oregon, USA) attached in the low intertidal zone in the wave-exposed areas at SH and BB. From these data we calculated high-tide water temperatures, defined as the mean of all readings during the period from $2 \mathrm{~h}$ before to $2 \mathrm{~h}$ after each high tide (as estimated from NOAA tide charts). For graphical presentation, these data were smoothed using a running means function that averaged each high-tide water temperature with those of the 2 preceding and 2 following high tides.

To assess variation in phytoplankton abundance, chl a concentrations were quantified from water samples collected at $\mathrm{SH}$ and BB on 3 to $14 \mathrm{~d}$ during each of the 5 barnacle growth periods ( $\mathrm{n}=33$ dates between 29 June and 8 September 1994). On sampling dates, 5 water samples were taken at low tide from the waveexposed areas at each site. Because the wave-protected areas at $\mathrm{SH}$ completely drained at low tide, no water samples were taken at this location. Limited sampling of wave-protected areas at BB at low tide indicated that chl a concentration varied minimally with wave exposure (Menge unpubl. data).

Samples were collected from a depth of $15 \mathrm{~cm}$ in acid-washed $250 \mathrm{ml}$ Nalgene dark bottles ( 5 bottles per site). Bottles were stored in a cooler with ice, returned to Hatfield Marine Science Center in Newport, Oregon, and processed according to established methods (Parsons et al. 1984, Menge et al. 1997a). We filtered a $50 \mathrm{ml}$ subsample from each collection bottle. Subsamples were first poured through a $100 \mu \mathrm{m}$ Nytex prefilter (to remove any large matter), and then filtered on a $25 \mathrm{~mm}$ glass-fiber filter that had previously been baked in a combustion oven at $450^{\circ} \mathrm{C}$ (to remove any organic contaminants). After filtering, the paper was removed with forceps and placed in a $15 \mathrm{ml}$ centrifuge tube. To extract chl $a, 10 \mathrm{ml}$ of $90 \%$ HPLC acetone was added to each tube, and tubes were stored in a dark freezer for $24 \mathrm{~h}$.

Prior to analysis, samples were removed from the freezer and warmed to room temperature in the dark. We centrifuged the samples for $5 \mathrm{~min}$, transferred the supernatant to a glass cuvette, and read its fluorescence in a Turner AU10 fluorometer. A second fluorescence reading was taken after adding 2 drops of $10 \%$ $\mathrm{HCl}$ to each cuvette. The concentration of chl a was calculated based on these 2 readings and an equation generated from calibration standards.

Statistical analysis. Although growth rates generally decline with age, previous authors have noted that the basal diameter of several barnacle species increased at a linear rate over much of their early life history (Crisp 1960, Bourget \& Crisp 1975, Crisp \& Bourget 1985). In our study, growth of Balanus glandula and Chthamalus dalli did not appear to slow until at least 3 to 4 mo after settlement (see 'Results'). We therefore assessed variation in short-term barnacle growth by comparing growth rates (i.e. slope of increase in basal diameter $\left[\mathrm{mm} \mathrm{d}^{-1}\right]$ ) among the 4 to 5 time intervals from late June to early September 1994.

In all analyses, growth plates were treated as the experimental units and barnacles on plates were regarded as sub-samples. We thus averaged the growth rate $(\mathrm{mm}$ 
$\mathrm{d}^{-1}$ ) from all individuals on a plate to obtain a mean for each plate within each site $\times$ time period combination. Plates were only included in the analysis if they had a complete set of measurements for $\geq 2$ individuals. Sample sizes thus varied among sites and analyses.

Since the growth of individual barnacles on plates was followed through time, data were analyzed in a repeated-measures analysis of variance (RM-ANOVA). Three separate RM-ANOVAs were conducted on the short-term growth rates of (1) Balanus glandula on natural settlement plates, (2) B. glandula on transplanted plates, and (3) Chthamalus dalli on transplanted plates. Site ( $\mathrm{SH}$ vs $\mathrm{BB}$ ) was regarded as a fixed effect in all models. The first analysis incorporated the additional factor of wave exposure (exposed vs protected), which was also treated as a fixed effect.

There are both univariate and multivariate approaches to repeated-measures designs (von Ende 1993). Although the univariate approach is more powerful, it requires that data exhibit homogeneity in the variance of the difference between all possible pairs of repeated measures (a condition known as sphericity). When sphericity is not met, $F$ statistics for the withinsubject factor are inflated, and it is necessary to use either the multivariate approach or decrease the degrees of freedom in the univariate analysis using the Huynh-Feldt adjustment (von Ende 1993).

We tested whether sphericity was met using Mauchly's sphericity test applied to the orthonormalized form of the variance-covariance matrix. The assumption was satisfied for the transplant study (growth of transplanted Balanus glandula and Chthamalus dalli), but not for the growth of B. glandula on natural settlement plates. In this case, we present the univariate results with more conservative Huynh-Feldt-adjusted p-values. In all cases, multivariate repeated-measures analyses are presented for comparison. As in all ANOVA designs, normality and homogeneity of variance are also required, and we tested these assumptions by visual inspection of normal probability plots and residual plots. In all cases the untransformed data satisfied these assumptions reasonably well.

If the RM-ANOVA indicated significant variation in growth between sites and/or among time periods, we conducted separate tests to determine which specific contrasts were significant. Within each time period we tested whether barnacle growth varied between sites by conducting a 2 sample $t$-test with a Bonferroniadjusted critical p-value to control for multiple comparisons across the 4 to 5 time periods. Within each site, we used ANOVA and the Tukey-Kramer procedure for multiple comparisons to identify significant differences in growth among time periods.

For the analysis of post-settlement mortality, the percent of settlers surviving on each plate after $\sim 25 \mathrm{~d}$ were arcsine square-root transformed and examined in a 3-way ANOVA with site, wave exposure, and settlement date as fixed effects. Replicate plates were removed from the analysis if they had fewer than 4 new settlers present at the beginning of the mortality period.

\section{RESULTS}

\section{Post-settlement mortality}

Mortality of Balanus glandula and Chthamalus dalli during their first $25 \mathrm{~d}$ on pitted plates was high $(49.9 \%$ overall), but variable (Fig. 2). Post-settlement mortality was apparently the result of physical stresses, because whelks and other predators were never observed on the growth plates (Sanford pers. obs.). Survivorship was generally lower at protected locations than at exposed locations, except at BB in June. Survivorship was lower at $\mathrm{SH}$ than at $\mathrm{BB}$ in June, but similar between sites in August. Thus, post-settlement mortality was dependent on the interaction of site, wave exposure, and settlement date (Table 1: site $\times$ exposure $\times$ date, $p=0.008$ ). High post-settlement mortality contributed to variation in barnacle size on the plates. Because individuals frequently died and were replaced by new settlers, plates quickly developed a mixture of barnacles of different ages and sizes.

\section{Allometric relationships and growth curves}

As expected, basal diameter and basal area were tightly correlated for both Balanus glandula (area = $-0.49+0.45$ [diameter] +0.65 [diameter] $^{2}, \mathrm{R}^{2}=0.99$, $\mathrm{n}=1145$ ) and Chthamalus dalli (area $=0.17+0.0059$

Table 1. Balanus glandula and Chthamalus dalli. Analysis of variance of the effects of site, wave exposure, and settlement date on survivorship of newly settled acorn barnacles (B. glandula and C. dalli combined). Dependent variable was arcsine square-root transformed percent of settlers surviving on each plate after $\sim 25 \mathrm{~d}$. p-values in bold indicate that factor is significant at $\alpha=0.05$

\begin{tabular}{|lrcrr|}
\hline Source & df & MS & \multicolumn{1}{c|}{$F$} & \multicolumn{1}{c|}{$\mathrm{p}$} \\
\hline Site & 1 & 0.564 & 10.41 & $\mathbf{0 . 0 0 1 7}$ \\
Exposure & 1 & 0.552 & 10.19 & $\mathbf{0 . 0 0 1 9}$ \\
Settlement date & 1 & 1.307 & 24.12 & $<\mathbf{0 . 0 0 0 1}$ \\
Site $\times$ Exposure & 1 & 0.079 & 1.47 & 0.2288 \\
Site $\times$ Date & 1 & 1.106 & 20.41 & $<\mathbf{0 . 0 0 0 1}$ \\
Exposure $\times$ Date & 1 & 0.323 & 5.97 & $\mathbf{0 . 0 1 6 3}$ \\
Site $\times$ Exposure $\times$ Date & 1 & 0.397 & 7.33 & $\mathbf{0 . 0 0 8 0}$ \\
Error & 103 & 0.054 & & \\
& & & & \\
\hline
\end{tabular}




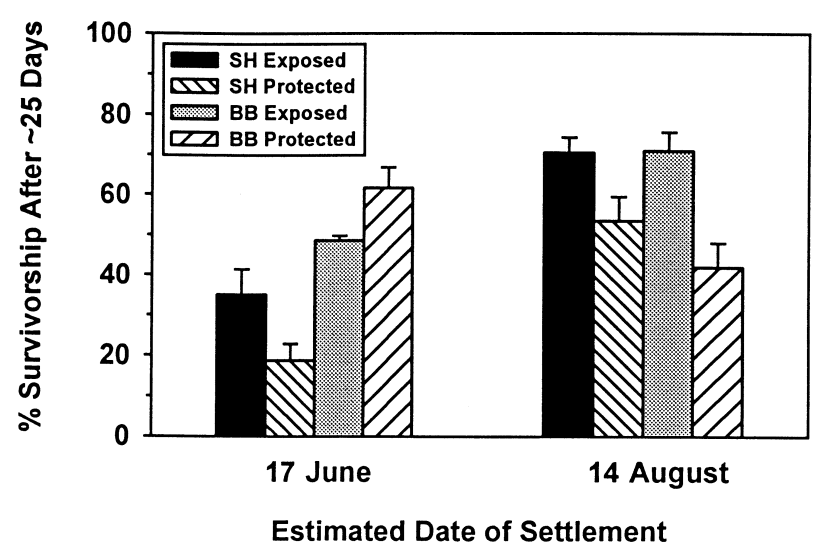

Fig. 2. Balanus glandula and Chthamalus dalli. Post-settlement mortality of barnacles on growth plates. Bars are the mean \% survivorship (+SEM) of newly settled barnacles ( $B$. glandula and C. dalli combined) after $\sim 25 \mathrm{~d}$ on shore ( $\mathrm{n}=13$ to 15 plates per site $\times$ exposure combination, each with 4 to 42 new settlers; mean $=18$ per plate). Mortality of cohorts settling on 17 June 1994 and 14 August 1994 ( \pm 6 d) was evaluated in 4 areas (Strawberry Hill [SH] exposed, SH protected, Boiler Bay [BB] exposed, and BB protected)

[diameter] +0.71 [diameter $]^{2}, \mathrm{R}^{2}=0.99, \mathrm{n}=531$ ). Consequently, for barnacles growing on transplanted plates, only basal areas were measured. Basal diameters used in the analysis of short-term growth were estimated using measured basal areas and the equations for the polynomial fits.

For both Balanus glandula and Chthamalus dalli, basal diameter increased rapidly during the summer before reaching a site-specific plateau by fall (Figs. 3 \& 4). Despite this general trend of rapid summer growth, there appeared to be short-term variation in growth within this season. In particular, growth rates of $B$. glandula appeared to slow at both sites in late July, before accelerating in August (Fig. 3).

A non-linear growth curve could be generated if barnacle growth rate were size-dependent. Growth could accelerate after individuals reached some threshold size, perhaps due to unknown interactions among body size, hydrodynamic boundary layers, and feeding efficiency (Crisp 1960). To test this hypothesis, we separated individual Balanus glandula into cohorts based on when they first appeared on the settlement plates. This analysis revealed that all cohorts exhibited a phase of reduced growth in late July, regardless of age or size (Fig. 3). For example, BB barnacles that settled a month apart (4 May and 3 June), and differed in size by $\sim 3 \mathrm{~mm}$, showed parallel fluctuations in short-term growth (Fig. 3A). These results suggest that variation in growth rate was the result of an external factor(s) and not a size-dependent growth trajectory.

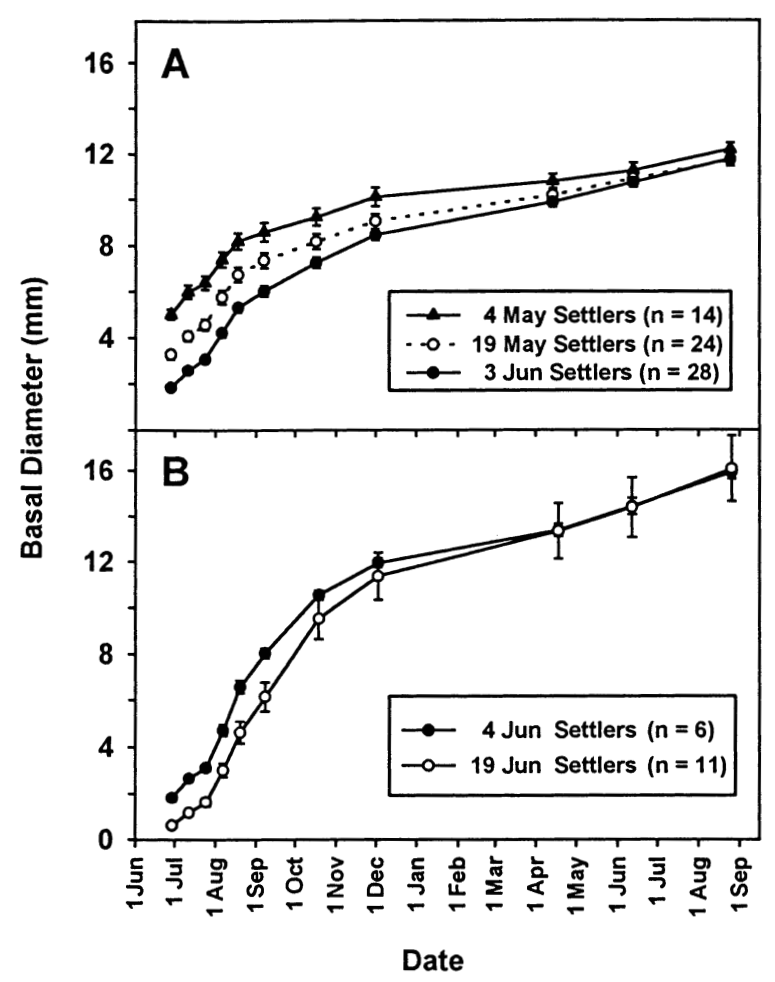

Fig. 3. Balanus glandula. Growth curves. Data are mean basal diameter $( \pm$ SEM) on successive sampling dates for all individuals that persisted on natural settlement plates from May/ June 1994 through late August 1995 at (A) Boiler Bay exposed, and (B) Strawberry Hill exposed. Growth trajectories are separated by date of settlement (estimated $\pm 6 \mathrm{~d}$ ). These individuals were a subset of those used in the shortterm growth study (Fig. 6)

\section{Oceanographic variation and predicted patterns of growth}

Based on these data, we assumed that, under constant environmental conditions, the basal diameter of Balanus glandula and Chthamalus dalli should increase at a roughly constant rate for at least the first few months after settlement. The results of other studies suggest that this may be a general pattern among barnacles (Crisp 1960, Bourget \& Crisp 1975, Crisp \& Bourget 1985). New shell material is added during each period of tidal immersion (Crisp \& Richardson 1975), and rate of addition is only minimally influenced by the molting cycle (Bourget \& Crisp 1975).

We thus examined variation in short-term growth by testing whether the rate of increase in basal diameter $\left(\mathrm{mm} \mathrm{d}^{-1}\right)$ varied among different time intervals. The influence of environmental factors was evaluated by comparing variation in barnacle growth rate with variation in chl a concentration, water temperature, and wave exposure. 


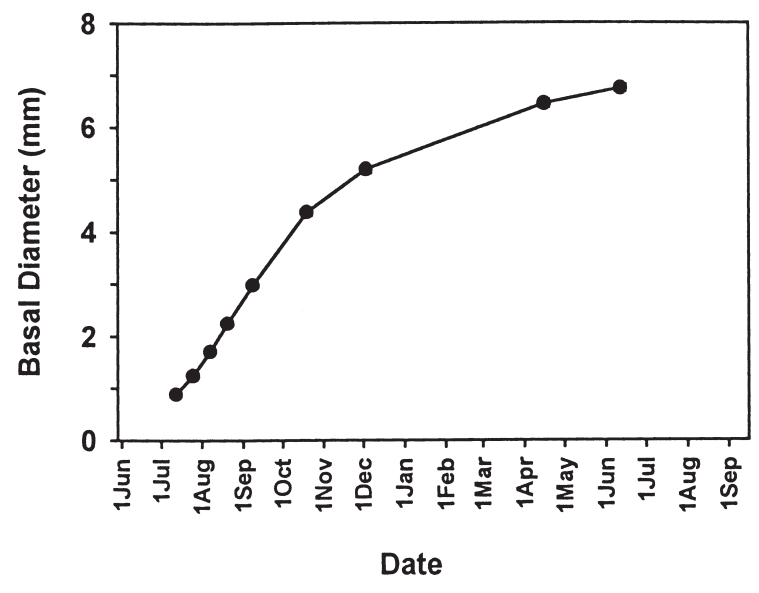

Fig. 4. Chthamalus dalli. Growth curve. Data are mean basal diameter on successive sampling dates for 59 individuals on 6 transplanted plates at Strawberry Hill exposed. All individuals settled in June 1994. Error bars (SEM) are smaller than data points
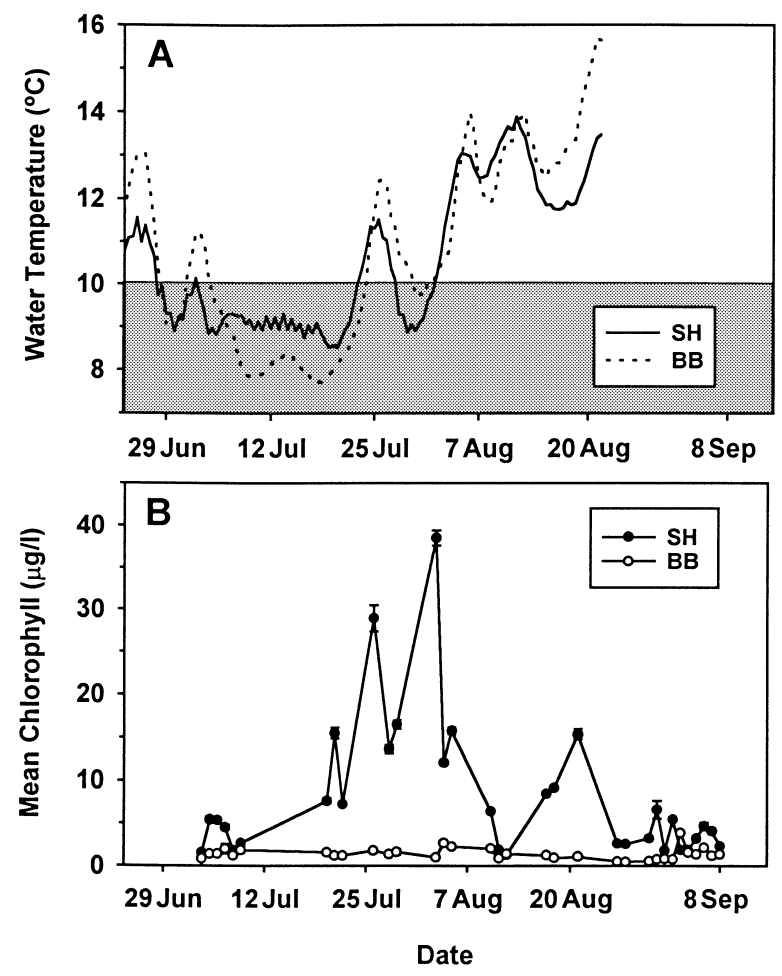

Fig. 5. Oceanographic conditions at Strawberry Hill (SH) and Boiler Bay (BB), summer 1994. (A) High-tide water temperatures (mean data-logger reading during period from $2 \mathrm{~h}$ before to $2 \mathrm{~h}$ after each high tide) at $\mathrm{SH}$ and BB. Data were smoothed using running means function (see 'Materials and Methods' for details). Shaded region indicates water temperatures characteristic of upwelling $\left(<10^{\circ} \mathrm{C}\right)$. Temperature records unavailable for period after 21 August. (B) Mean chlorophyll a concentration $( \pm \mathrm{SEM})$ in water samples collected from exposed areas at $\mathrm{SH}(\bullet)$ and $\mathrm{BB}(\mathrm{o})(\mathrm{n}=5$ samples per site per date)
During this study, there was a persistent upwelling event lasting most of July. This upwelling event was marked by strong northerly winds and water temperatures which remained well below $10^{\circ} \mathrm{C}$ for several weeks (Fig. 5A, see also Menge et al. 1997b). Winds favoring upwelling ceased in late July, and soon after a large phytoplankton bloom was observed at SH. Very high levels of chl a were recorded at SH on the 6 dates sampled during this 'bloom period' (Fig. 5B: 25 July to 7 August). In contrast, chl a remained low and fairly consistent at $\mathrm{BB}$ throughout the summer. If barnacle growth were strongly linked to phytoplankton abundance, we would predict that growth rates would be greatest during the bloom period at $\mathrm{SH}$, and consistently lower at BB. We assumed that there would be little, if any, lag between increased consumption and growth because food has a residency time of $<8 \mathrm{~h}$ in barnacle guts (Crisp 1964, Anderson 1994).

\section{Short-term growth on natural settlement plates: Balanus glandula}

On natural settlement plates, wave exposure had a significant effect on the growth rate of Balanus glandula, regardless of site (Table 2: exposure, $\mathrm{p}<0.001$, site $\times$ exposure, $p=0.32$ ). As expected, barnacles grew more quickly in areas that experienced greater flows. By early September, wave-exposed barnacles at $\mathrm{SH}$ had mean basal diameters $1.6 \times$ greater than wave-protected barnacles (Fig. 6). Similarly, wave-exposed barnacles at BB had diameters $2.5 \times$ greater than those in the protected area.

Balanus glandula growth varied among time periods and was dependent on both site and wave exposure (Fig. 6, Table 2: time $\times$ site $\times$ exposure, $\mathrm{p}<0.001$ ). In both the exposed and protected areas at $\mathrm{SH}$, growth was greater during the bloom period (25 July to 7 August) than during the first 2 periods (29 June to 12 July and 12 to 25 July), but did not differ from the final 2 periods ( 7 to 20 August, and 20 August to 8 September) (Tukey-Kramer, p > 0.05).

Surprisingly, Balanus glandula growth showed similar variation through time at the BB exposed area, where little variation in chl a was recorded (Figs. 5B \& 6). Growth was greater during the 'bloom period' (25 July to 7 August) than during either the first 2 periods or the final period (20 August to 8 September) (TukeyKramer, $\mathrm{p}<0.05)$. At the BB protected area, there was little variation in growth through time (Fig. 6B).

Also surprising was the observation that growth rate did not vary significantly between $\mathrm{SH}$ exposed and $\mathrm{BB}$ exposed during the bloom period (25 July to 7August; $t$-test, $\left.t_{19}=-0.799, \mathrm{p}=0.43\right)$, despite the fact that a dramatic increase in chl a was recorded at $\mathrm{SH}$, but not at 

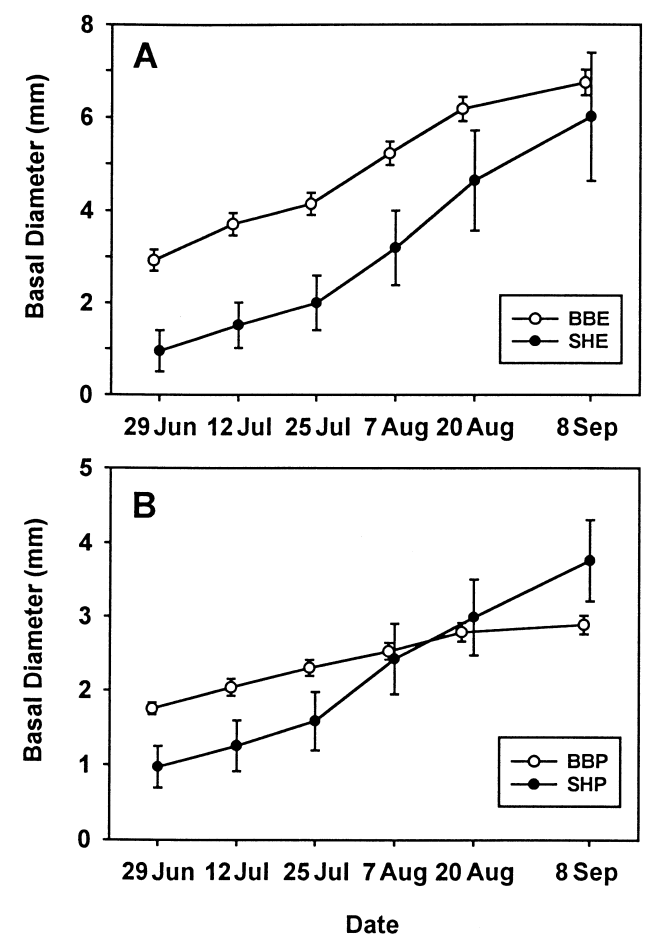

Fig. 6. Balanus glandula. Growth of naturally settling barnacles on mid-intertidal plates at Strawberry Hill and Boiler Bay. Data are means $( \pm$ SEM) of mean basal diameter on 7 to 14 plates in (A) wave-exposed and (B) wave-protected areas. Starting sizes differed on 29 June because many barnacles settled earlier at BB than at SH. Sample sizes varied with number of plates that had $\geq 2$ individuals persisting in all 5 periods. SHE $=$ Strawberry Hill exposed $(n=7), \mathrm{BBE}=$ Boiler Bay exposed $(n=14)$, SHP $=$ Strawberry Hill protected $(n=8)$, BBP $=$ Boiler Bay protected $(n=10)$

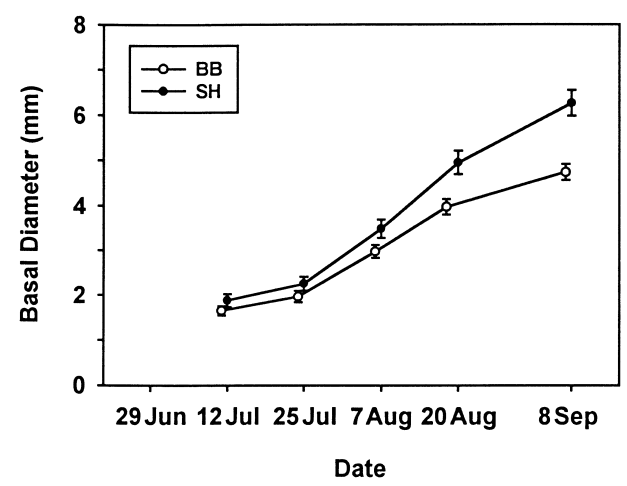

Fig. 7. Balanus glandula. Growth on mid-intertidal plates transplanted from common source to exposed areas at Strawberry Hill (SH) and Boiler Bay (BB). Data are means $( \pm$ SEM) of mean basal diameter on 7 plates per site, each with $\sim 13$ individuals per plate

BB (Figs. 5B \& 6). Interestingly, during the 2 periods after the bloom ( 7 August to 8 September), the mean growth rate at $\mathrm{SH}$ was $0.4 \times$ and $1.6 \times$ greater (respectively) than at BB ( $t$-tests, $\mathrm{p}<0.01)$.

\section{Short-term growth on transplanted plates: Balanus glandula}

Growth patterns of Balanus glandula transplanted to $\mathrm{SH}$ exposed and BB exposed areas were very similar to those of barnacles settling naturally at these sites (Fig. 7). Since plates were transplanted on 9 July,

Table 2. Balanus glandula. Repeated-measures analysis of variance of effects of site and wave exposure on growth during 5 consecutive time periods. Barnacles were allowed to settle naturally on replicate plates in wave-exposed and wave-protected areas at Strawberry Hill and Boiler Bay. Dependent variable was mean rate of increase in basal diameter $\left(\mathrm{mm} \mathrm{d}^{-1}\right)$ for all individuals on a replicate plate. Data did not exhibit homogeneity of treatment differences variance (test for sphericity, $p=0.006$ ). Univariate results are therefore presented with Huynh-Feldt (H-F)-adjusted probabilities, and multivariate results are provided for comparison. $p$-values in bold indicate that factor is significant at $\alpha=0.05$. Num $=$ numerator; Den $=$ denominator

\begin{tabular}{|c|c|c|c|c|c|c|c|c|c|}
\hline $\begin{array}{l}\text { (A) Between subjects } \\
\text { Source }\end{array}$ & \multicolumn{3}{|c|}{$\mathrm{df}$} & \multicolumn{2}{|c|}{ MS } & \multicolumn{2}{|c|}{$F$} & & $\mathrm{p}$ \\
\hline Site & \multicolumn{3}{|c|}{1} & \multicolumn{2}{|c|}{0.01478} & \multicolumn{2}{|c|}{22.41} & & $<0.0001$ \\
\hline Exposure & \multicolumn{3}{|c|}{1} & \multicolumn{2}{|c|}{0.05854} & \multicolumn{2}{|c|}{88.75} & & $<0.0001$ \\
\hline Site $\times$ Exposure & \multicolumn{3}{|c|}{1} & \multicolumn{2}{|c|}{0.00066} & \multirow{2}{*}{\multicolumn{2}{|c|}{1.01}} & & 0.3228 \\
\hline Error & & 35 & & & 0066 & & & & \\
\hline \multicolumn{10}{|l|}{ (B) Within subjects } \\
\hline Source & df & & MS & $F$ & $\begin{array}{c}\text { H-F } \\
\text { p-value }\end{array}$ & $\underset{\mathrm{df}}{\mathrm{Num}}$ & $\begin{array}{c}\text { Den } \\
\text { df }\end{array}$ & $\begin{array}{c}\text { Wilks' } \\
\lambda\end{array}$ & $\mathrm{p}$-value \\
\hline Time & 4 & & 0.01020 & 69.83 & $<0.0001$ & 4 & 32 & 0.1304 & $<0.0001$ \\
\hline Time $\times$ Site & 4 & & 0.00351 & 24.01 & $<0.0001$ & 4 & 32 & 0.1872 & $<0.0001$ \\
\hline Time $\times$ Exposure & 4 & & 0.00344 & 23.54 & $<0.0001$ & 4 & 32 & 0.2948 & $<0.0001$ \\
\hline Time $\times$ Site $\times$ Exposure & 4 & & 0.00096 & 6.58 & 0.0001 & 4 & 32 & 0.6049 & 0.0024 \\
\hline Error & 140 & & 0.00015 & & & & & & \\
\hline
\end{tabular}




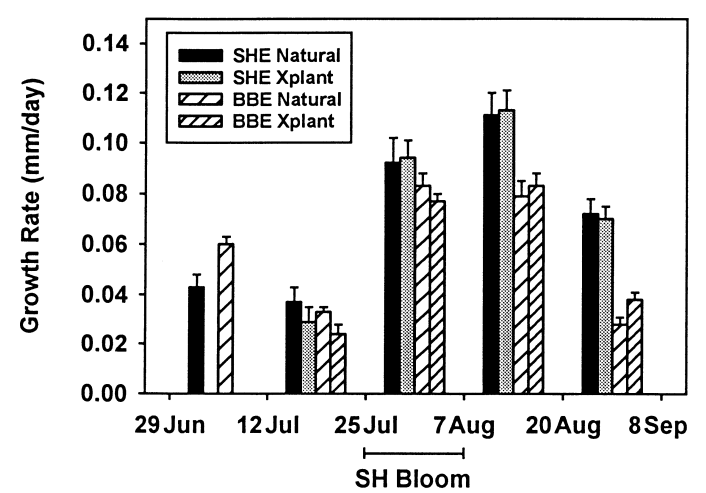

Fig. 8. Balanus glandula. Summary of growth rates during 5 consecutive periods. Bars are mean growth rate (+SEM) in $\mathrm{mm} \mathrm{d}^{-1}$; SHE $=$ Strawberry Hill exposed, BBE $=$ Boiler Bay exposed, Natural $=$ natural settlement plates, Xplant $=$ transplanted plates. Major phytoplankton bloom was recorded at

SH during the period 25 July to 7 August (see Fig. 5B)

growth was quantified in 4 periods rather than 5 . Growth rates differed among the 4 time periods, and this variation was dependent upon site (Table 3: time $\times$ site, $\mathrm{p}=0.0067)$. At the $\mathrm{SH}$ exposed area, growth rate during the bloom period (25 July to 7 August) was greater than during the preceding upwelling period (12 to 25 July), but did not differ from the final 2 periods ( 7 August to 8 September) (Tukey-Kramer, p < 0.05). At the $\mathrm{BB}$ exposed area, growth during the bloom period was greater than during the upwelling period (25 July to 7 August) and the final period (20 August to 8 September) (Tukey-Kramer, p <0.05).

As on natural settlement plates, Balanus glandula growth did not vary significantly between sites during the bloom period (Fig. 7 ; $t$-test, $t_{12}=-2.26, \mathrm{p}=0.043>$ than the Bonferroni-adjusted critical $p$-value $=0.0125$ ), but was greater at $\mathrm{SH}$ than $\mathrm{BB}$ during the following 2 periods ( $t$-tests, $\mathrm{p}<0.01)$.

In summary, growth rate of Balanus glandula on both natural settlement plates and transplanted plates was low in all areas during the upwelling event and more than doubled when upwelling ceased (Figs. 5 \& 8). This increase in growth coincided with a large phytoplankton bloom that occurred at SH (25 July through 7 August). Contrary to our prediction, barnacles at BB grew at the same rate as those at $\mathrm{SH}$ during this period, despite no bloom being recorded at BB. Barnacles did, however, grow faster at $\mathrm{SH}$ than $\mathrm{BB}$ during the 2 periods following the peak bloom period (Fig. 8).

\section{Short-term growth on transplanted plates: Chthamalus dalli}

Temporal variation in Chthamalus dalli growth was less dramatic than in Balanus glandula (Fig. 9). Nevertheless, growth rates differed among the 4 time periods, and this variation was dependent upon site (Table 4: time $\times$ site, $\mathrm{p}=0.0097$ ). At the $\mathrm{SH}$ exposed area, growth during the bloom period was greater than during the preceding upwelling period (Tukey-Kramer, $\mathrm{p}<0.05$ ), but did not differ from the final 2 periods. At the BB exposed area, growth during the bloom period was greater than during any of the other periods (Tukey-Kramer, p <0.05).

Comparing growth between sites, Chthamalus dalli grew faster at $\mathrm{SH}$ than at $\mathrm{BB}$ during the period from 7 to 20 August ( $t$-test, $t_{11}=-3.850, \mathrm{p}=0.0027$ ), but growth rates did not differ between sites during the other 3 periods (Fig. 9, $t$-tests, $\mathrm{p}>0.10$ ). Thus, as with Balanus glandula, C. dalli growth was low during the upwelling event and subsequently increased. How-

Table 3. Balanus glandula. Repeated-measures analysis of variance of effects of site on growth of transplanted barnacles during 4 consecutive time periods. Replicate plates were transplanted to wave-exposed areas at Strawberry Hill and Boiler Bay. Dependent variable was mean rate of increase in basal diameter $\left(\mathrm{mm} \mathrm{d}^{-1}\right)$ for all individuals on a replicate plate. Data exhibited homogeneity of treatment differences variance (test for sphericity, $p=0.88$ ). Univariate results are therefore presented with unadjusted probabilities, and multivariate results are provided for comparison. $\mathrm{p}$-values in bold indicate that factor is significant at $\alpha=0.05$

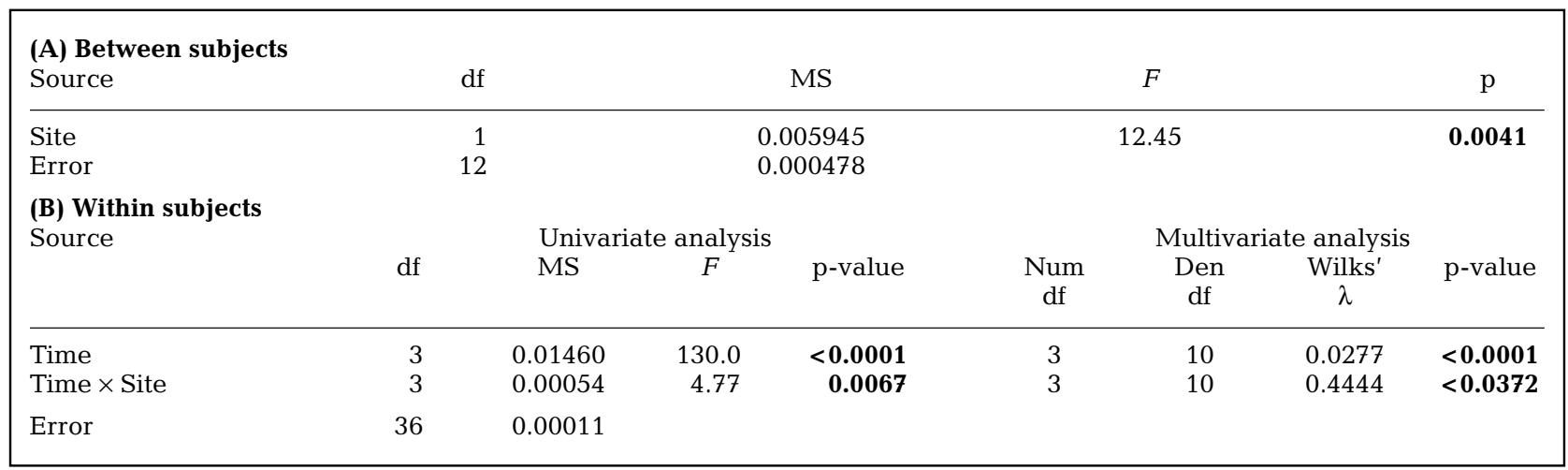




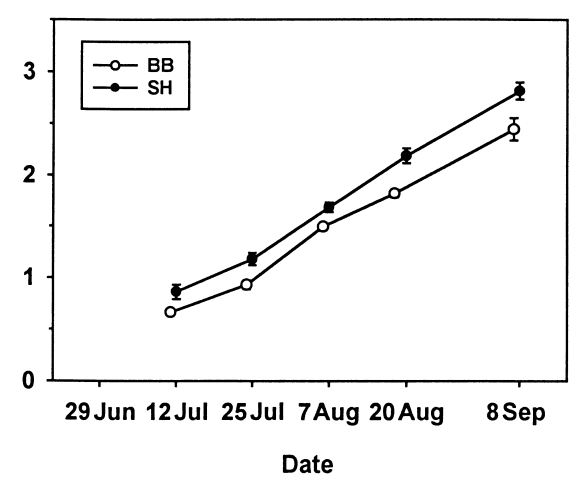

Fig. 9. Chthamalus dalli. Growth on mid-intertidal plates transplanted from common source to exposed areas at Strawberry Hill and Boiler Bay. Data are means $( \pm$ SEM) of the mean basal diameter on 7 plates per site, each with $\sim 34$ individuals per plate

ever, there was little variation between sites, despite the strong differences in chl a concentrations.

\section{Longer-term growth rates}

At wave-exposed locations, Balanus glandula attained a much larger adult size at SH than at BB (Fig. 3). Barnacles that settled in May and June 1994 were $2.0 \mathrm{~mm}$ larger at $\mathrm{SH}$ by late October, and $4.1 \mathrm{~mm}$ larger at $\mathrm{SH}$ by the following August.

We followed a separate set of Balanus glandula that settled on exposed plates at $\mathrm{SH}$ and $\mathrm{BB}$ during August 1994 (Fig. 10A). By mid-April 1995 (after $\sim 8$ mo of growth) these individuals were significantly larger at $\mathrm{SH}$ than BB ( $t$-test, $t_{22}=-13.92, \mathrm{p}<0.001$; per plate mean basal area $\pm \mathrm{SEM}=91.0 \pm 3.1 \mathrm{~mm}^{2}$ vs $35.5 \pm 2.3 \mathrm{~mm}^{2}$ ).
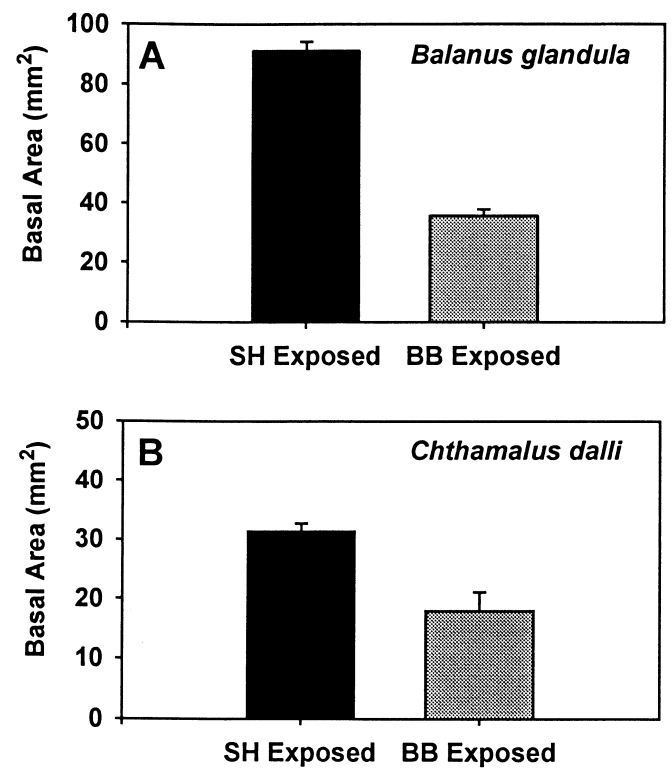

Fig. 10. (A) Balanus glandula and (B) Chthamalus dalli. Longterm growth in exposed areas at Strawberry Hill and Boiler Bay. Bars are mean basal area (+SEM). (A) For B. glandula, individuals settling in August 1994 were measured in April 1995 following $\sim 8$ mo of growth $(\mathrm{SH}, \mathrm{n}=13$ plates; $\mathrm{BB}, \mathrm{n}=11)$. (B) For C. dalli, individuals on transplanted plates were measured in June 1995 after $\sim 1$ yr of growth $(\mathrm{SH}, \mathrm{n}=7$ plates; $\mathrm{BB}$, $\mathrm{n}=3$ due to plate loss)

For Chthamalus dalli, we measured the basal area of all individuals that persisted on transplanted plates from June 1994 to June 1995 (Fig. 10B). After approximately $1 \mathrm{yr}$ of growth, $C$. dalli at $\mathrm{SH}$ were significantly larger than those at $\mathrm{BB}\left(t\right.$-test, $t_{8}=-4.65$, $\mathrm{p}=0.002$; per plate mean basal area $\pm \mathrm{SEM}=31.3 \pm$ $1.6 \mathrm{~mm}^{2}$ vs $17.9 \pm 2.4 \mathrm{~mm}^{2}$ ).

Table 4. Chthamalus dalli. Repeated-measures analysis of variance of effects of site on growth during 4 consecutive time periods. Replicate plates were transplanted to wave-exposed areas at Strawberry Hill and Boiler Bay. Dependent variable was mean rate of increase in basal diameter $\left(\mathrm{mm} \mathrm{d}^{-1}\right)$ for all individuals on a replicate plate. Data exhibited homogeneity of treatment differences variance (test for sphericity, $p=0.76$ ). Univariate results are therefore presented with unadjusted probabilities, and multivariate results are provided for comparison. p-values in bold indicate that factor is significant at $\alpha=0.05$

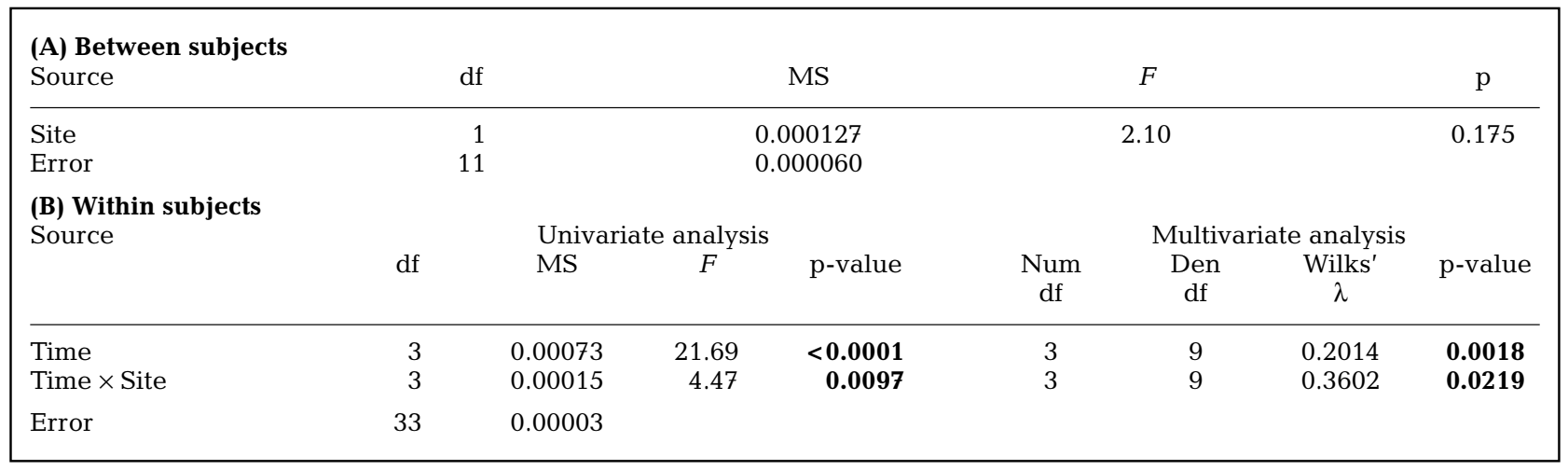




\section{DISCUSSION}

Growth rates of Balanus glandula and Chthamalus dalli varied dramatically at a variety of spatial and temporal scales and appeared to be correlated with a complex set of oceanographic conditions, including wave exposure, abundance of planktonic food, and water temperature.

\section{Effects of wave exposure on growth}

Within each site, barnacles grew more rapidly in wave-exposed than in wave-protected habitats. Quantification of relative flow rates within these areas confirmed that the exposed areas generally experienced greater flows (Menge et al. 1996). Many studies have found that barnacles grow faster in areas of higher flow, presumably because of the increased delivery of suspended particles to passively feeding barnacles (Hatton \& Fischer-Piette 1932, Moore 1935, Crisp 1960, Bertness et al. 1991, Sanford et al. 1994, Bustamante et al. 1995, Leonard et al. 1998). Barnacles on waveexposed plates may also have experienced longer submergence times and hence greater opportunities for feeding. Although plates were positioned at the same tidal height, wave swell in exposed areas shortened periods of aerial exposure on some days (Sanford pers. obs.). Exposed areas may also have experienced reduced thermal stress, as suggested by the lower rates of post-settlement mortality in these habitats (Fig. 2).

\section{Effects of phytoplankton abundance}

Determining whether barnacle growth rates were directly correlated with phytoplankton abundance was the central goal of this study. Our results documented extreme short-term variation in barnacle growth rates; in the 2 wk immediately following an extended upwelling period, growth rates in wave-exposed areas increased by 2.5 to $3.3 \times$ for Balanus glandula and by 1.6 to $2.1 \times$ for Chthamalus dalli (Figs. $7 \&$ 8). At $\mathrm{SH}$, this increase in growth was associated with a dramatic 3- to 5 -fold increase in chl a concentrations (Fig. 5B).

However, 2 lines of evidence suggest that phytoplankton abundance did not fully explain variation in barnacle growth. First, a well-defined spike in barnacle growth was not apparent at SH. Although Balanus glandula growth increased at SH during the peak bloom period (25 July to 7 August), it remained high during the following 2 periods ( 7 to 20 August, 20 August to 8 September), despite chl a levels dropping sharply (Figs. 5B \& 8). Second, growth rates at BB also increased dramatically following the upwelling event, although there was no increase in chl a concentration there (Figs. 5B \& 8).

Although water samples were not collected on a daily basis, it seems unlikely that a phytoplankton bloom occurred and went unnoticed at BB. The bloom at $\mathrm{SH}$ lasted at least $10 \mathrm{~d}$, during which the nearshore waters were strikingly brown in color. On $6 \mathrm{~d}$ throughout this period (26, 28, 29 July, 3, 4, 5 August), chl a concentrations were very high at $\mathrm{SH}$ and consistently low at BB.

\section{Potential influence of zooplankton and water temperature}

These patterns suggest that factors in addition to phytoplankton may have influenced barnacle growth rates. One possibility is that barnacle growth responded to changes in zooplankton concentration. Although we are aware of no data regarding the diet of Balanus glandula or Chthamalus dalli, stomach-content analyses and laboratory feeding observations show that zooplankton is consumed by many barnacle species. Semibalanus balanoides, an Atlantic barnacle similar in size and habitat to $B$. glandula, readily consumed $300 \mu \mathrm{m}$ barnacle nauplii in the laboratory (Crisp \& Southward 1961). The stomachs of field-collected individuals also contained a variety of invertebrate larvae and small crustaceans (Barnes 1959). Stomach contents of $S$. cariosus and B. nubilis, 2 larger intertidal barnacles common in Oregon, included barnacle nauplii and cyprids, small copepods, detritus, detached algal filaments, and diatoms (Barnes 1959, Zardus et al. 1991, Navarrete \& Wieters 2000).

Barnacles are thus capable of consuming a variety of suspended foods representing a large range of particle sizes (Anderson 1994). A comparison of 5 barnacle species in Chinese waters suggested that phytoplankton was dominant in the stomachs of smaller species, whereas zooplankton was the primary food of larger species (Jianping et al. 1996). Although this pattern suggests that the size of particles captured may be a function of body size, we are aware of only 1 study that has examined whether the composition of a barnacle's diet changes with growth and development. In the gooseneck barnacle Pollicipes polymerus, gut-content analysis suggested that recently settled individuals (1 to $6 \mathrm{~mm}$ across) were more dependent on detritus and diatoms than larger individuals whose diet included copepods and other crustaceans (Lewis 1981). Even so, more than half of the small individuals sampled had recently consumed crustaceans.

It is thus possible that the newly settled barnacles on our plates were large enough to consume zooplankton. In a laboratory flowtank, small Semibalanus bala- 
noides (mean basal diameter $=3.7 \mathrm{~mm}$ ) readily captured relatively large pieces of macroalgae (1000 to $2000 \mu \mathrm{m}$ in length) (Trager et al. 1990). Thus, even small Balanus glandula and Chthamalus dalli may be capable of capturing early-stage barnacle nauplii (200 to $300 \mu \mathrm{m}$ in length; Strathmann 1987), and perhaps larger zooplankton as well. If this were the case, then variation in zooplankton concentration may have contributed to patterns of barnacle growth.

As an indicator of spatial and temporal variations in zooplankton abundance, we examined data collected from barnacle settlement plates attached within the mid-intertidal zone at the same 4 study areas $(\mathrm{SH}$ exposed, SH protected, BB exposed, BB protected; $\mathrm{n}=$ 5 plates per area). These $10 \times 10 \mathrm{~cm}$ plates were covered with a textured surface (Safety-Walk ${ }^{\mathrm{TM}}, 3 \mathrm{M}$, St. Paul, Minnesota, USA) and deployed for $30 \mathrm{~d}$ periods as part of a long-term monitoring program (Menge unpubl. data). Data from the periods of our study suggest that settlement of both Balanus glandula and Chthamalus dalli was very low during upwelling (22 June to 22 July) and dramatically higher during the upwelling relaxation (22 July to 20 August) (Figs. 5 $\& 11)$. These results are consistent with the offshore advection of larvae during upwelling and onshore transport during periods of upwelling relaxation (Roughgarden et al. 1988, 1991, Farrell et al. 1991).

Whereas chl a differed strongly between sites during the upwelling relaxation, patterns of settlement varied little between sites, implying similar water-column concentrations of barnacle larvae. In addition, although phytoplankton abundance peaked and returned to lower levels within 2 to $3 \mathrm{wk}$, concentrations of barnacle larvae may have remained high throughout August at both sites. Plates collected on 20 August had high densities of both recently settled juveniles and cyprids (Fig. 11). Because cyprids metamorphose shortly after settlement, their presence on the plates indicates that barnacle larvae were abundant in the water column on or just before 20 August. To the extent that high concentrations of cyprids are indicative of onshore transport of a variety of zooplankton, these results imply that the period of enhanced barnacle growth at both sites was strongly associated with an increase in zooplankton concentrations. Therefore, the increase in barnacle growth during the relaxation of upwelling may have resulted from an increase in the concentration of both phytoplankton and zooplankton. Analyses of barnacle stomach contents, from individuals spanning a wide range of sizes would be very informative and are planned for future studies.

Increased water temperature may be an additional factor that contributed to enhanced barnacle growth rates. Water temperatures were consistently at or below $9^{\circ} \mathrm{C}$ during the July upwelling event and climbed to

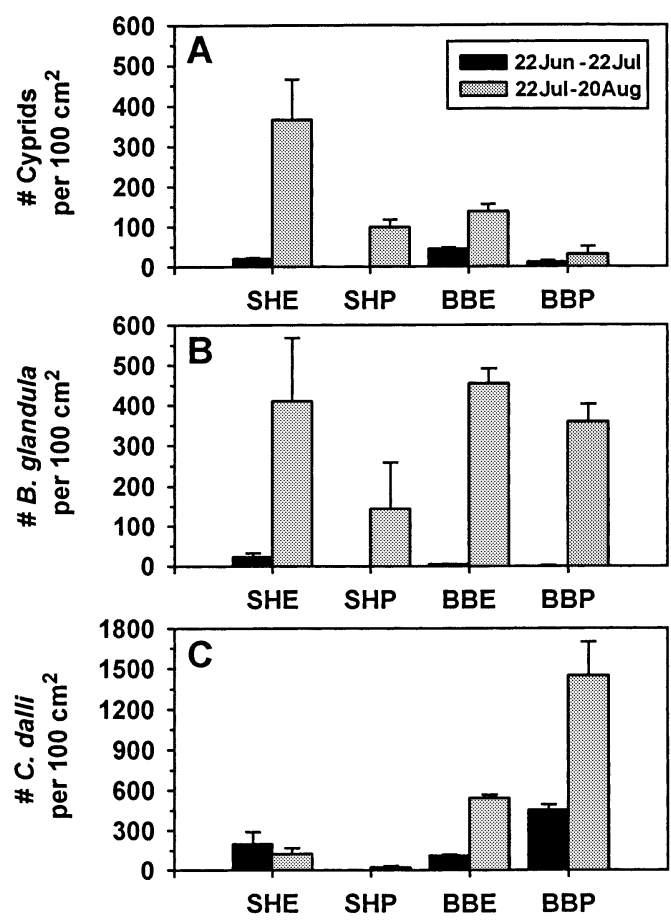

Fig. 11. Balanus glandula and Chthamalus dalli. Mid-intertidal barnacle settlement, summer 1994. Mean density (+SEM) of (A) cyprids, (B) newly settled B. glandula, and (C) newly settled $C$. dalli on $10 \times 10 \mathrm{~cm}$ textured plates deployed for $\sim 30 \mathrm{~d}$ during a persistent upwelling event $(22$ June to 22 July) and an upwelling relaxation (22 July to 20 August). Plates were deployed in all 4 study areas $(\mathrm{n}=5$ plates per area); SHE $=$ Strawberry Hill exposed, SHP = Strawberry Hill protected, BBE $=$ Boiler Bay exposed, BBP $=$ Boiler Bay protected

$>13^{\circ} \mathrm{C}$ during the upwelling relaxation (Fig. 5A). Upwelling temperatures were thus lower than winter water temperatures, which rarely dip below $10^{\circ} \mathrm{C}$ at these sites (Sanford unpubl. data). Barnacle growth rate is assumed to increase at higher temperatures because of enhanced cirral activity, food intake, and assimilation (Crisp \& Bourget 1985, Anderson 1994, Sanford et al. 1994). Therefore, faster growth rates during the upwelling relaxation may have arisen from the combined benefits of more food and warmer water temperatures.

\section{Between-site variation in growth}

By the time growth rates began to plateau in the late fall, Balanus glandula had attained a significantly larger body size at SH than at BB (Fig. 3). Measurements of longer-term growth indicated a similar pattern; after 8 mo growth at $\mathrm{SH}, B$. glandula were 2.6× larger than at BB (Fig. 10A). For Chthamalus dalli, individuals were $1.7 \times$ larger at $\mathrm{SH}$ than at $\mathrm{BB}$ after $1 \mathrm{yr}$ 
growth (Fig. 10B). Although reproductive output was not quantified in this study, faster-growing barnacles typically have larger egg masses and allocate a greater proportion of resources to reproduction (Bertness et al. 1991). Monthly water samples taken from 1993 to the present suggest that phytoplankton concentrations are typically higher at SH during most months of the year (Menge et al. 1996, Menge unpubl. data).

These results thus support the hypothesis that consistently higher levels of productivity at $\mathrm{SH}$ translate into stronger 'bottom-up' forces (Menge 1992, Menge et al. 1997b); both Balanus glandula and Chthamalus dalli grew more rapidly and attained a larger adult size at SH. Previous studies indicate that the recruitment and growth of mussels Mytilus californianus and $M$. trossulus are also higher at $\mathrm{SH}$ than at BB (Menge 1992, Menge et al. 1997b). The consistently higher prey production at $\mathrm{SH}$, in turn, appears to support higher densities of sea stars that exert more intense predation pressure (Menge et al. 1994, 1996, 1997b, Navarrete \& Menge 1996).

Efforts are under way to expand the scale of these studies to test whether variation in productivity generates similar differences among multiple sites along the coasts of Oregon and California (Menge et al. 1997b, and unpubl. data). The results of this study suggest that incorporating the additional influence of zooplankton and water temperature into large-scale studies of bottom-up influences may improve our ability to explain variation among intertidal communities.

Acknowledgements. We are grateful to D. Bermudez, B. Daley, E. Londahl, and M. Wilkin for field and laboratory assistance. We also thank M. Hixon, J. Lubchenco, G. Somero, and 3 anonymous reviewers for helpful comments on this manuscript. This research was funded by a National Science Foundation (NSF) predoctoral fellowship to E.S. and by NSF grants OCE92-17459 (B.A.M., P. Wheeler and P. T. Strub), the Andrew W. Mellon Foundation, and a Wayne and Gladys Valley Professorship in Marine Biology (B.A.M.). This is contribution number 20 of the Partnership for Interdisciplinary Studies of Coastal Oceans (PISCO): A Long-Term Ecological Consortium funded by the David and Lucile Packard Foundation.

\section{LITERATURE CITED}

Anderson DT (1994) Barnacles: structure, function, development and evolution. Chapman \& Hall, London

Baird D, Evans PR, Mile H, Pienkowski MW (1985) Utilization by shorebirds of benthic invertebrate production in intertidal areas. Oceanogr Mar Biol Annu Rev 23:573-597

Barnes H (1959) Stomach contents and microfeeding of some common cirripedes. Can J Zool 37:231-236

Barnes H, Powell HT (1950) The development, general morphology and subsequent elimination of barnacle populations, Balanus crenatus and B. balanoides, after a heavy initial settlement. J Anim Ecol 19:175-179

Bertness MD, Gaines SD, Bermudez D, Sanford E (1991)
Extreme spatial variation in the growth and reproductive output of the acorn barnacle Semibalanus balanoides. Mar Ecol Prog Ser 75:91-100

Bertness MD, Gaines SD, Yeh SM (1998) Making mountains out of barnacles: the dynamics of acorn barnacle hummocking. Ecology 79:1382-1394

Bourget E, Crisp DJ (1975) Factors affecting deposition of the shell in Balanus balanoides. J Mar Biol Assoc UK 55: 231-250

Bustamante RH, Branch GM, Eekhout S, Robertson B, Zoutendyk P, Schleyer M, Dye A, Hanekom N, Keats D, Jurd M, McQuaid C (1995) Gradients of intertidal productivity around the coast of South Africa and their relationships with consumer biomass. Oecologia 102:189-201

Connell JH (1961) The influence of interspecific competition and other factors on the distribution of the barnacle Chthamalus stellatus. Ecology 42:710-723

Connolly SR, Roughgarden J (1998) A latitudinal gradient in northeast Pacific intertidal community structure: evidence for an oceanographically based synthesis of marine community theory. Am Nat 151:311-326

Connolly SR, Roughgarden J (1999) Theory of marine communities: competition, predation, and recruitment-dependent interaction strength. Ecol Monogr 69:277-296

Crisp DJ (1960) Factors influencing growth-rate in Balanus balanoides. J Anim Ecol 29:95-117

Crisp DJ (1964) An assessment of plankton grazing by barnacles. In: Crisp DJ (ed) Grazing in terrestrial and marine environments. Blackwell Scientific, Oxford, p 251-264

Crisp DJ, Bourget E (1985) Growth in barnacles. Adv Mar Biol 22:199-244

Crisp DJ, Richardson CA (1975) Tidally produced internal bands in the shell of Elminius modestus. Mar Biol 33: 155-160

Crisp DJ, Southward AJ (1961) Different types of cirral activities of barnacles. Phil Trans R Soc 243:271-308

Denny MW (1988) Biology and the mechanics of the waveswept environment. Princeton University Press, Princeton, NJ

Duggins DO, Simenstad CA, Estes JA (1989) Magnification of secondary production by kelp detritus in coastal marine ecosystems. Science 245:170-173

Farrell TM, Bracher D, Roughgarden J (1991) Cross-shelf transport causes recruitment to intertidal populations in central California. Limnol Oceanogr 36:279-288

Gaines S, Brown S, Roughgarden J (1985) Spatial variation in larval concentrations as a cause of spatial variation in settlement for the barnacle, Balanus glandula. Oecologia $67: 267-272$

Gosselin LA, Qian PY (1996) Early post-settlement mortality of an intertidal barnacle: a critical period for survival. Mar Ecol Prog Ser 135:69-75

Hatton H, Fischer-Piette E (1932) Observations et expériences sur le peuplement des côtes rocheuses par les cirripèdes. Bull Inst Océanogr Monaco 592:1-15

Jarrett JN, Pechnik JA (1997) Temporal variation in cyprid quality and juvenile growth capacity for an intertidal barnacle. Ecology 78:1262-1265

Jianping L, Ruxing C, Zhouxing Q, Sifeng W, Jianwei Q (1996) Stomach contents of the several barnacles in Zhoushan waters. Donghai Mar Sci 14:28-34

Leonard GH, Levine JM, Schmidt PR, Bertness MD (1998) Flow-driven variation in intertidal community structure in a Maine estuary. Ecology 79:1395-1411

Lewis CA (1981) Juvenile to adult shift in feeding strategies in the pedunculate barnacle Pollicipes polymerus (Sowerby) (Cirripedia, Lepadomorpha). Crustaceana 41:14-20 
Menge BA (1991) Relative importance of recruitment and other causes of variation in rocky intertidal community structure. J Exp Mar Biol Ecol 146:69-100

Menge BA (1992) Community regulation: under what conditions are bottom-up factors important on rocky shores? Ecology 73:755-765

Menge BA, Berlow EL, Blanchette CA, Navarrete SA, Yamada SB (1994) The keystone species concept: variation in interaction strength in a rocky intertidal habitat. Ecol Monogr 64:249-286

Menge BA, Daley BA, Wheeler PA (1996) Control of interaction strength in marine benthic communities. In: Polis GA, Winemiller KO (eds) Food webs: integration of patterns and dynamics. Chapman \& Hall, New York, p 258-274

Menge BA, Daley BA, Wheeler PA, Strub PT (1997a) Rocky intertidal oceanography: an association between community structure and nearshore phytoplankton concentration. Limnol Oceanogr 42:57-66

Menge BA, Daley BA, Wheeler PA, Dahlhoff E, Sanford E, Strub PT (1997b) Benthic-pelagic links in rocky intertidal communities: bottom-up effects on top-down control? Proc Natl Acad Sci USA 94:14530-14535

Menge BA, Daley BA, Lubchenco J, Sanford E, Dahlhoff E, Halpin PM, Hudson G, Burnaford JL (1999) Top-down and bottom-up regulation of New Zealand rocky intertidal communities. Ecol Monogr 69:297-330

Moore HB (1935) The biology of Balanus balanoides. IV. Relation to environmental factors. J Mar Biol Assoc UK 20: 279-307

Moore HB (1936) The biology of Balanus balanoides. V. Distribution in the Plymouth area. J Mar Biol Assoc UK 20: 701-716

Navarrete SA, Menge BA (1996) Keystone predation and interaction strength: interactive effects of predators on their main prey. Ecol Monogr 66:409-429

Navarrete SA, Wieters EA (2000) Variation in barnacle recruitment over small scales: larval predation by adults and maintenance of community pattern. J Exp Mar Biol Ecol 253:131-148

Editorial responsibility: Ronald Karlson (Contributing Editor), Newark, Delaware, USA
Paine RT (1980) Food webs: linkage, interaction strength, and community infrastructure. J Anim Ecol 49:667-685

Paine RT (1994) Marine rocky shores and community ecology: an experimentalist's perspective. Ecology Institute, Oldendorf/Luhe

Parsons TR, Maita Y, Lalli CM (1984) A manual of chemical and biological methods for seawater analysis. Pergamon Press, New York

Pineda J (1994) Spatial and temporal patterns in barnacle settlement rate along a southern California rocky shore. Mar Ecol Prog Ser 107:125-138

Ricciardi A, Bourget E (1999) Global patterns of macroinvertebrate biomass in marine intertidal communities. Mar Ecol Prog Ser 185:21-35

Roughgarden J, Gaines S, Possingham H (1988) Recruitment dynamics in complex life cycles. Science 241:1460-1466

Roughgarden J, Pennington JT, Stoner D, Alexander S, Miller $\mathrm{K}$ (1991) Collisions of upwelling fronts with the intertidal zone: the cause of recruitment pulses in barnacle populations of central California. Acta Oecol 12:35-51

Sanford E (1999) Regulation of keystone predation by small changes in ocean temperature. Science 283:2095-2097

Sanford E, Bermudez D, Bertness MD, Gaines SD (1994) Flow, food supply and acorn barnacle population dynamics. Mar Ecol Prog Ser 104:49-62

Strathmann MF (1987) Reproduction and development of marine invertebrates of the Northern Pacific coast. University of Washington Press, Seattle, WA

Trager GC, Hwang JS, Strickler JR (1990) Barnacle suspension-feeding in variable flow. Mar Biol 105:117-127

von Ende CN (1993) Repeated-measures analysis: growth and other time-dependent measures. In: Scheiner SM, Gurevitch J (eds) Design and analysis of ecological experiments. Chapman \& Hall, London, p 113-137

Wethey DS (1984) Spatial patterns in barnacle settlement: day to day changes during the settlement season. J Mar Biol Assoc UK 64:687-698

Zardus JD, Braithwaite LF, Maurer BA (1991) Diet of the barnacle Balanus nubilus in the presence and absence of Metridium senile. Am Zool 31:103

Submitted: November 19, 1999; Accepted: May 30, 2000 Proofs received from author(s): November 30, 2000 